\title{
Research on Agricultural Ecological Factors Information Technology based on Internet +
}

\section{Hongwei Zhu}

Jilin Agricultural Science and Technology University, Jilin, Jilin, 132000

\author{
Keywords: Agricultural Ecological Factors, Internet +, Information Technology
}

\begin{abstract}
In the "Internet +" agriculture era, with the help of emerging information technologies such as the Internet, cloud computing and big data, the entire industrial chain of agricultural production and business activities has been optimized and upgraded. This has become the direction of agricultural reform. Taking agricultural information as the research object, this paper studies the correlation between various environmental factors in the agricultural information ecology for the first time by studying the agricultural information itself and the ecological phenomena associated with the outside world, summarizes the current ecological performance of agricultural information and builds the "Internet +" agriculture In the era of ecological balance of agricultural information, in accelerating the process of agricultural informatization, at the same time, provide real-time accurate information support for the implementation of "Internet +" agricultural action plan.
\end{abstract}

\section{Introduction}

The Internet era, information and material, and energy all together become the pillar resources for the development of human society. Information is an indispensable element of people and their activities. It interacts with people and social environment to form a special ecological environment. Information ecology is a new field of science formed by the mutual penetration of ecology and information science. From the perspective of integrity in ecology, the systematic analysis of the ways and effects of the utilization of various kinds of information within a given organization is made. Based on this, BA Nardi et al. Proposed that only under the specific conditions and background, can information ecological research be linked with information environment to solve information ecological problems in different situations so as to achieve the purpose of better playing the role of ecological information. In our country, the first research on information ecology is academician Zhang Xinshi. He believes that information ecology should have the advantages of high-tech and information theory of information science at the same time. It focuses on how to apply information technology to modeling and analyzing natural ecosystems and biosphere problems, Simulation and prediction of the problem. Scholars who further study the information ecology --- Chen Shu defines the information ecology as the relationship between the information itself and its surroundings, that is, the information ecosystem should contain the interaction between information, people and the environment. Zhang Fuxue proposed that information ecology is a system composed of people, practices, values and technologies in a given regional environment. The most important thing in the system is not technology, but human technology using technology.

\section{Agricultural Information Ecology}

Under the background of "Internet +" agriculture, agricultural accounting services are faced with a higher level of breadth, depth and cost and efficiency requirements. Combining the application of emerging technologies such as big data, cloud computing, mobile Internet and Internet of Things, agricultural information ecosystem The concept came into being. As with the information ecology, the information ecology of agriculture is also composed of the three elements of information, information subject and information environment, and takes the information demand of "Internet plus" agricultural action plan as the motive force. With information technology as the main means, the agricultural information ecology The ultimate goal of balance. In view of the particularity of 
agricultural production and management, the ecological characteristics of agricultural information show unique characteristics.

The effective implementation of the "Internet + " agricultural action plan needs to make full use of a new generation of information technologies such as big data, cloud computing and mobile Internet to achieve cross-border integration of information technology and agriculture and build a modern agricultural production and operation mode based on the Internet platform. New agricultural market. This coincides with the idea of information ecology, that is, the use of technological advances to achieve the efficient integration of information and data, and thus seek the balance of the entire information ecosystem and stable development. Therefore, driven by the "Internet +" agriculture, agricultural accounting will no longer be confined to traditional financial accounting areas. The new generation of information technology will further broaden the sources of agricultural accounting information. First of all, as far as information content is concerned, the breadth and difficulty of collecting biological information materials will continue to increase on the basis of the peculiarities of agricultural production and management. At the same time, accounting personnel should consider both financial Data, but also take into account the non-financial data; Second, as far as the agricultural accounting boundary is concerned, agricultural accounting is gradually moving towards the edge of management accounting, that is, information data should include both internal information collection business organizations, but also include the background of big data Under the enterprise external environment data, such as industry information data, government preferential policies, market supply and demand; Finally, the form of information, agricultural accounting information will cover structured information data, semi-structured information data and unstructured information data , Audio, video, images and other information and information will be gradually incorporated into the scope of information collection with the promotion of computer technologies such as mobile Internet and Internet of Things [8].

The main body of agricultural information is divided into two main categories: information supply and demand. The main body of information supply includes not only the provider of original information but also the further processing of information and data, namely the information decomposer in information ecological theory. In the era of mobile Internet, with the development of large-scale customization and personalized service, the demand for information in enterprises has seriously exceeded the supply of available information. From the individual of departmental units to the external customers, any collection of information points can be provided to enterprises Benefit from the budget, the effective decision-making information. In the background that accounting industry faces the challenge of financial accounting to managerial accounting transformation, especially in the implementation of "Internet + " agricultural action plan, the accounting in agricultural industry is about to move. Taking the exploration and practice of "Internet +" agriculture in Jiangsu Province as an example, its online marketing activities of agricultural products are showing a diversified development trend. Whether it is through the online trading activities of third-party platforms represented by Taobao or self- Fresh marketing of agricultural products distribution center city, have reflected from the side of the agricultural information subject tends to be more complex [9]. As the traditional agricultural accounting, cost accounting to the integration of production and management efficiency, accounting information a comprehensive summary will be crucial, and provide the value of the information of the main body of the information, with the expansion of production and operation scale and increasingly complex.

\section{Agricultural information ecological imbalance performance}

With the transfer of information in different stages of agricultural information ecosystem, the various ecological factors in the system will inevitably lead to imbalance of the system due to the different stages of development. As a result, the information ecosystem function or utility can not be more Good play, eventually leading to an increase in agricultural production and management costs as well as the reduction of production and management efficiency.

Information overload in information ecology theory means that the amount of information obtained by a system or individual exceeds the capacity that the system can handle or load, making 
the information people unable to obtain the valuable information they need. As far as the agricultural accounting information ecology is concerned, the overloading of agricultural information inevitably exists, and its fundamental reason is determined by the peculiarities of agricultural production and operation. Taking the agricultural information of agricultural enterprises as an example, as the state attaches great importance to the agricultural industry and the construction of agricultural informatization and modernization, agricultural enterprises have sprung up. On the one hand, from the viewpoint of agricultural enterprises themselves, in order to cater to the " On-demand production and management ". In particular, to seek sustainable development of enterprises from the" Internet + "agriculture process, enterprises need to continuously receive various kinds of information data from inside and outside themselves to form information data" physical type platter The phenomenon, combined with the current slow pace of development of agricultural accounting industry, led accounting practitioners face the challenge of information overload and failure to obtain effective information data smoothly. On the other hand, relevant accounting rules and regulations will disclose the financial status and business results of enterprises There are compulsory requirements, thus increasing the relevant stakeholders to identify the required information, included and the use of difficulty [12]. The above status of agricultural information overload will cause the entire information ecosystem imbalance results.

\section{4. "Internet +" Construction of Agricultural Information Ecological Balance in Agricultural Times}

Agricultural information resources are the core content of the entire information transfer process, and the connection point between information suppliers and disseminators and demanders. As the most important part of the agricultural information ecosystem, agricultural information resource management is particularly important. First of all, in view of the peculiarity of agriculture in our country, most production and management entities do not have a unified and standardized concept of financial accounting. In addition to the increasingly complicated information available, traditional agricultural information is still confined to financial data such as costs and benefits Therefore, in the development of agricultural information resources, especially in the era of "Internet +" agriculture, we should take precautions against different measurement standards and different aspects of information transmission in order to obtain objective and reliable sources of information At the same time, in accordance with the principle of specific screening, the effective integration of information has been obtained from the source as far as possible to prevent the complexity of the agricultural production and operation of objects caused by the loss of effective information, and invalid information inflow occurred, thus ensuring Accounting information of the green, ecological, pollution-free. Secondly, construct a network system of agricultural information sharing. With the launch of the "Internet +" agricultural action plan, the popularization of "12316" "San Nong" hotline and the application of online media such as agricultural information network, the transparency of agricultural information is constantly improving. However, given the geographical features of agricultural production and operation, Sexual and cyclical characteristics, a unified system of agricultural information sharing network has not been established. In addition, accounting standards for small and medium-sized agricultural enterprises and new rural economic organizations (farmer cooperatives, family farms, etc.) and other agricultural production and operation entities are not unified and the definition of information property rights is unclear. As a result, the disclosed accounting information and undisclosed There is a gap between quantity and quality of accounting information, which makes it difficult for the disclosure of agricultural information and the real disclosure. Therefore, setting up a reasonable agricultural information sharing network system will help to speed up the speed of information dissemination, reduce the transaction costs of information and enhance the production and management efficiency.

The theory of information ecology holds that the information demanders are the recipients of information and the decomposers and suppliers of information. In other words, the identities of the information suppliers and the demand entities can be freely converted. The information circulation and transmission in the information ecosystem needs each Harmony of ecological factors. However, 
in actual production and operation activities, due to the difference of knowledge or cognition, users of agricultural information have not yet understood or understood the essence of them. In view of this situation, first of all, different agricultural production and management subjects targeted accounting knowledge training, including traditional accounting theory and policy, laws and regulations, as well as information technology, information processing technology learning; secondly, for information disclosure issues, should Around the information disclosure, public rights, the production of information products and their use of value and other content, all-round, multi-angle study and exchange, and gradually realize the main body of information supply and demand from closed, narrow to rational, mature demand and consumer changes.

\section{Conclusion}

Agricultural information ecological research is an emerging research topic, which spans the agricultural accounting, ecology, information science and other disciplines. At present, there is not a complete and systematic concept of agricultural information in our country. The classification of agricultural information (including agricultural information) and the non-uniform agricultural accounting standards, the existence of information redundancy and monopoly phenomenon make the construction of agricultural information ecological balance a complex project. The integration of emerging information technologies such as cloud computing, big data and mobile Internet technologies with agricultural production and operation activities will help to strengthen the development and management of agricultural accounting information resources. By standardizing the supply and demand of information subjects and improving the ecological environment of information systems, Standardization Management of Agricultural Accounting Information.

\section{Acknowledgement}

Project: Science and Technology Development Project of Jilin Province Natural Science Foundation of China: Application of Wireless Sensor Network to the Monitoring Technology of Ginseng Growth Environment Parameter.

Project No.: 20150101099JC

Jilin Province Science and Technology Agency Development Plan Science and Technology Innovation Center base and technology service platform construction project: Internet + ginseng ecological factor analysis and prediction information service platform.

Key disciplines of Jilin Agricultural Science and Technology Training Program: Research on Ginseng Growth Environment Parameter Monitoring System Based on Internet of Things.

Project No.: Jilin Agricultural Academy of Sciences [2015] No. X097

\section{References}

[1] Gao Guangyao. China's Internet of Things technology chain and industrial chain coordinated development [J]. Science and technology progress and countermeasures. 2014 (12)

[2] Xing Dan, Yao Junming. Internet of Things for the Medical Industry: Concept, Architecture and Key Technologies [J]. Internet of Things Technology. 2014 (11)

[3] Zhao Na, Yuan Jiabin, Xu Han. Review of Intelligent Transportation Systems [J]. Computer Science. 2014 (11)

[4] Li Xiufeng, Chen Shouhei, Guo Leifeng. Technological Innovation of Agricultural Information Service in the Age of Big Data [J]. Journal of Agricultural Science and Technology of China. 2014 (04)

[5] Wang Jianong. Research on Agricultural Information Service Model from the Perspective of Informationization [J]. Information Systems Engineering. 2014 (07)

[6] Fang Yuan, Lin Dunan. Review of Wisdom Medical Research [J]. New Economy. 2014 (19) 